\title{
EXPERIENCE OF DISSOCIATIVE TRANCE DISORDER IN ADOLESCENTS
}

\author{
Moh. Zainol Rachman, Kissa Bahari, Farida Halis \\ School of Health Sciences (Poltekkes), \\ Ministry of Health, Malang
}

\begin{abstract}
BACKGROUND: Dissociative trance disorder (DTD) frequently occurred in the community, particularly among teenagers. This study aimed to the experience of dissociative trance disorder in adolescents.

SUBJECTS AND METHOD: This was a qualitative study using phenomenological approach conducted in Malang, East Java. The study subjects were eight adolescents who had experienced dissociative trance disorder. The data were collected by in-depth interview.

RESULTS: The predisposing factors of DTD included: a) Biological factors, trance history of family; b) Psychological factors: more than one time of trance history, victim/witness physical abuse, trauma or mental pressure from family/environment, unstable mind and feeling suspicious to others, easily disappointed to others, repression coping habit; and c) Socio-cultural factors: mystical thought/occult, watching horror movies, creepy situation memory. Precipitating stressors of DTD were trouble or distress of family or school. Experience responses before DTD included: (1) Hearing rowdy/noisy voice; (2) Noisy/unclear sound, (3) Hot ear feeling; (4) Hot air condition (5) Uneasy feeling; (6) Confusion; (7) Scare; (8) Frantic, (9) Anger; (10) Heavy head; (11) Dizziness as if pulled by others; (12) Heavy body; (13) Numb; (14) Cramps; (15) Dark ambient view; and (16) Restless. Experience responses during DTD included unconsciousness and amnesia. Experience responses after DTD included headache, body ache, unfocused mind, silence, tiresome, confusion, uneasy feeling, and weakness.

CONCLUSION: This study identify biological, psychological, and sociocultural predisposing factors for DTD among adolescents. Precipitation stressors include problem in the family or school. Experience responses before DTD include maladaptive behavior and feeling, and physical complaints. Experience responses during DTD include unconsciousness and amnesia. Experience responses after DTD include the change of feeling, behavior, and physical complaints. It is recommended to create an environment around adolescents that is free from violence and distress.
\end{abstract}

Keywords: adolescence, dissociative trance disorder 